Check for updates

Cite this: Chem. Commun., 2020, 56,14211

Received 21st July 2020,

Accepted 18th October 2020

DOI: $10.1039 / \mathrm{dOcc04973e}$

rsc.li/chemcomm

\section{Electrocatalytic oxidative $Z / E$ isomerization of a stilbene favoured by the presence of an electroactive persistent radical $\dagger$}

\author{
Paula Mayorga-Burrezo, (D) *a Christian Sporer, ${ }^{a}$ J. Alejandro de Sousa, (ID ${ }^{a b}$ \\ Nicola Capra, (iD a Klaus Wurst, ${ }^{C}$ Núria Crivillers, (iD a Jaume Veciana (D) a and \\ Concepció Rovira (D) *a
}

A push-pull-functionalized stilbene has been prepared, with an electroactive perchlorotriphenylmethyl (PTM॰) radical and dimethylamine units as electron-withdrawing and -donating moieties, respectively, showing an electrocatalytic redox-induced $Z \rightarrow E$ isomerization where the open-shell nature of $\mathrm{PTM}^{\bullet}$ plays a key role in the isomerization ocurrance.

The rise of molecular machines has entailed a growing interest in the field of molecular switches, thanks to the key role the latter may play in those sophisticated systems. ${ }^{1}$ Actually, the development of bistable molecules that undergo reversible conversions between their isomers has been a recurrent topic within the scientific community. Among them, particular attention has been devoted to the so-called photoinduced molecular switches, ${ }^{2}$ based on the light-driven $(E / Z)$ isomerization phenomenon. Several advantages, including high spatiotemporal precision or cleanness, ${ }^{3,4}$ justify the extensive use of this external stimulus to induce and modulate structural or morphological transitions on the chemical systems. As a result, many are the reports on photoswitchable double bonds that are found in the literature. See for instance: $\mathrm{C}=\mathrm{C}$ (e.g. stilbene) ${ }^{5}$ $\mathrm{N}=\mathrm{N}$ (e.g. , azobenzene), ${ }^{6,7}$ or $\mathrm{C}=\mathrm{N}$ (e.g. hydrazone). ${ }^{8}$ However, $(E / Z)$ isomerization reactions of such molecules may require severe photoirradiation conditions, ${ }^{9,10}$ limiting their use to those applications where intense emission is required.

\footnotetext{
${ }^{a}$ Department of Molecular Nanoscience and Organic Materials, Institut de Ciència de Materials de Barcelona (ICMAB-CSIC)/CIBER-BBN, Campus Universitari de Bellaterra, E-08193, Cerdanyola, Barcelona, Spain.E-mail: mayorga@vutbr.cz, cun@icmab.es

${ }^{b}$ Laboratorio de Electroquimica, Departamento de Química, Facultad de Ciencias, Universidad de los Andes, 5101 Mérida, Venezuela

${ }^{c}$ Institute of General, Inorganic and Theoretical Chemistry, University of Innsbruck, Center for Chemistry and Biomedicine, Innrain 80-82, A-6020 Innsbruck, Austria

$\dagger$ Electronic supplementary information (ESI) available: Synthesic details, experimental procedures and additional spectroscopic and X-ray data. CCDC 1906103. For ESI and crystallographic data in CIF or other electronic format see DOI: 10.1039/docc04973e
}

In a complementary way, it is known that redox reactions can lower the rotation barrier around a double bond by increasing its single-bond character. In fact, electron-transfer-induced $(E / Z)$ isomerizations have been demonstrated in hydrazone ${ }^{11,12}$ or stilbene derivatives, either through the formation of radical cations ${ }^{13,14}$ or radical anions. ${ }^{15-17}$ Furthermore, fast isomerizations can be achieved when catalytic mechanisms involving radical species are activated, as proved for azobenzenes ${ }^{18,19}$ and stilbene-based structures. ${ }^{20}$ Consequently, recent advances in molecular machines point at geometric isomerizations triggered by redox reactions as an alternative to photoinduced stimulation. ${ }^{21}$ For this reason, the design and development of new molecules with suitably substituted double bonds and stable $(E / Z)$ configurations is required. Up to now, to the best of our knowledge, all the studied systems presented electroactive moieties that generate either radical anion or radical cation intermediates upon electron transfer phenomena. Thus, the derived radical charged species were the ones playing a key role on the isomerization process. In this new approach, we address the use of a neutral radical molecule to investigate the impact of the radical character of the starting compound on the isomerization process.

Perchlorotriphenylmethyl $\left(\mathrm{PTM}^{\bullet}\right)$ radical unit has proved to be an excellent choice when considering chemical redox switches with optical (linear and nonlinear) and magnetic response. ${ }^{22-24}$ Some of us recently demonstrated irreversible $E \rightarrow Z$ isomerizations for two PTM-based stilbene derivatives. ${ }^{25}$ However, not redox but photo- and thermal-activated processes were investigated in that occasion. Further to this, nothing was said about the radical character since only the hydrogenated $(\alpha \mathrm{H}$-PTM) analogues were considered. On the other hand, some of us also reported the key role that $\mathrm{PTM}^{\bullet}$ group can play for the stabilization of a vicinal charge defect generated upon oxidation. ${ }^{26}$ Thus, these previous results motivated us to explore which could be the effect of the electroactive $\mathrm{PTM}^{\bullet}$ moiety on a redox mediated $(E / Z)$ isomerization. With this aim, a new donor-acceptorfunctionalized stilbene dyad, [PTM-DMA $]^{\bullet}$ in Scheme 1, with 

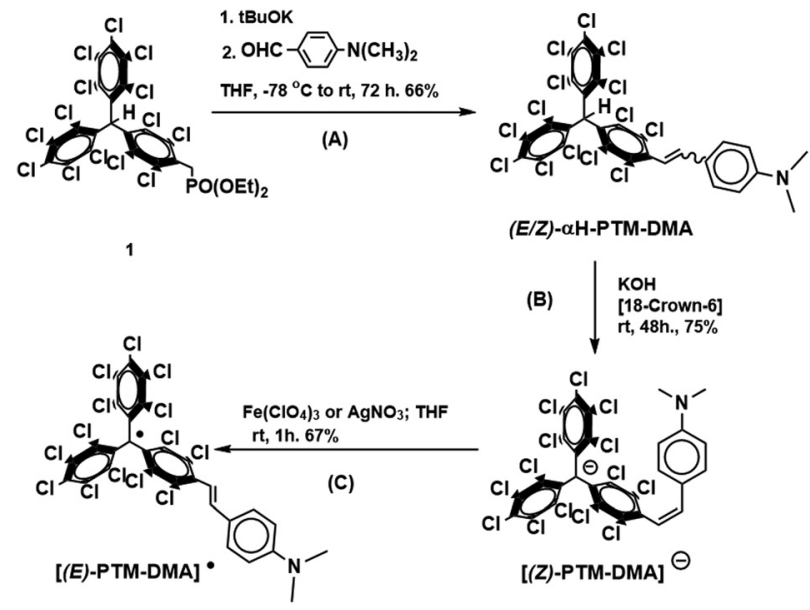

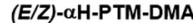
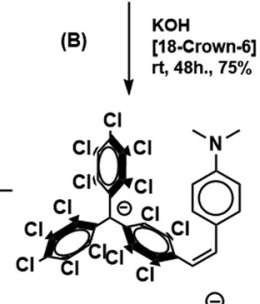

[(Z)-PTM-DMA] ${ }^{\ominus}$

Scheme 1 Synthesis of [(E)-PTM-DMA $]^{\bullet}$

$\mathrm{PTM}^{\bullet}$ as electron-acceptor was synthesized and characterized. $N, N$-Dimethylanyline (DMA) was chosen as strong electrondonor moiety, in order to facilitate the oxidation process based on a previous reports on vinylene-bridged PTM-donor derivatives studies with different amine groups. ${ }^{27,28}$ Additionally, its hydrogenated version ( $\alpha \mathbf{H}$-PTM-DMA, see Scheme 1) has also been studied, to gain further insights into the influence of the open-shell character on the phenomenon under study.

The synthetic procedure of [PTM-DMA ${ }^{\bullet}$ started with a Horner-Wadsworth-Emmons coupling (Scheme 1, reaction A) between the phosphonate precursor $\mathbf{1}^{29}$ and 4-dimethylaminebenzaldehyde, yielding $\boldsymbol{\alpha H}$ HPM-DMA. Remarkably, a different $(E / Z)$ isomeric mixture was obtained depending on the working conditions. According to ${ }^{1} \mathrm{H}-\mathrm{NMR}$ monitoring, a 25/75 ratio of $E / Z$ isomers was achieved when the synthesis and the subsequent work-up were performed under daylight conditions (Fig. S1, ESI $\dagger$ ). On the contrary, a considerably increase of $E / Z$ ratio (95/5), was achieved under light exclusion (Fig. S2, ESI $\dagger$ ). As previously said, these findings were associated with the $E \rightarrow Z$ photoisomerization (Fig. S3, ESI $\dagger$ ) and the subsequently blocked $Z \rightarrow E$ back conversion previously reported for $\alpha$ H-PTM stilbene compounds. ${ }^{25}$

Starting from a 15/85 (E/Z)- $\alpha$ H-PTM-DMA mixture, a deprotonation with $\mathrm{KOH}$ in presence of [18-crown-6] was then carried out (Scheme 1, reaction B) and, consequently, the corresponding anion ([PTM-DMA $]^{-}$) was generated. Suitable single crystals of [PTM-DMA $]^{-}$for X-ray analysis were grown by slow diffusion of hexane into a $\mathrm{CH}_{2} \mathrm{Cl}_{2}$ solution of 18-crown-6 $\mathrm{K}^{+}$ [PTM-DMA] $^{-}$(see ESI, $\dagger$ Section S3). The crystal structure unambiguously revealed the formation of the (Z)-isomer; i.e. [(Z)-PTM-DMA $]^{-}$(Fig. 1A). The solid-state structure of this salt consists in a one-dimensional coordination polymer with the carbanions and their related counterions in alternating positions along the crystallographic $a$ axis (Fig. 1B). Interestingly, a double coordination of each [(Z)-PTM-DMA $]^{-}$unit with two different $\mathrm{K}^{+}[18$-crown-6] ions was observed.

Electrochemical properties of the resulting $[(Z) \text {-PTM-DMA }]^{-}$ were investigated by cyclic voltammetry (Fig. 1C) and two reversible processes were observed: $E_{\text {red }}^{1 / 2}=-0.66 \mathrm{~V}\left(\nu s . \mathrm{Fc} / \mathrm{Fc}^{+}\right)$
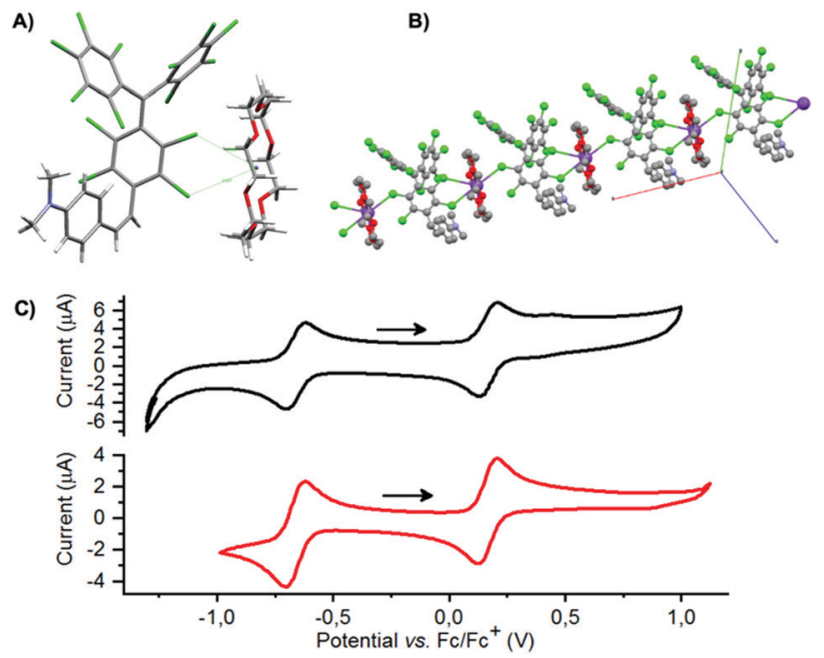

Fig. 1 (A) Asymmetric unit in the crystal structure of [(Z)-PTM-DMA] showing both the anion and the $\mathrm{K}^{+}[18$-crown-6] counterion. Disordered $\mathrm{CH}_{2} \mathrm{Cl}_{2}$ molecules have been omitted for clarity. (B) View of the polymeric chain formed along the crystallographic a axis. (C) Cyclic voltammograms (ca. $0.1 \mathrm{mM} / 0.2 \mathrm{M}^{\mathrm{TBA}-\mathrm{PF}_{6}}$ in $\mathrm{CH}_{2} \mathrm{Cl}_{2}$ ) of [(Z)-PTM-DMA] ${ }^{-}$(black) and [(E)-PTM-DMA] (red) recorded under inert atmosphere at r.t. Scan rate $=$ $0.1 \mathrm{~V} \mathrm{~s}^{-1}$. WE $=$ Au wire, $\mathrm{RE}=\mathrm{Ag}$ wire, $\mathrm{CE}=\mathrm{Pt}$ wire.

corresponding to the $\mathrm{PTM}^{-} / \mathrm{PTM}^{\bullet}$ redox couple ${ }^{30}$ and $E_{\mathrm{ox}}{ }^{1 / 2}=0.16 \mathrm{~V}$, related to the DMA/DMA ${ }^{\bullet+}$ pair. $^{27}$ According to these data, chemical oxidation of [(Z)-PTM-DMA $]^{-}$was performed, in order to obtain the same configuration in the [PTM-DMA] radical. $\mathrm{Fe}\left(\mathrm{ClO}_{4}\right)_{3}$ and $\mathrm{AgNO}_{3}$ were indistinctively used as oxidizing agents (Scheme 1, reaction C). Electron spin resonance (ESR) and UV-Vis electronic absorption spectroscopy fully confirmed the isolation of a radical species (see ESI, $\dagger$ Section S4 and Table S1) upon addition of one equivalent of the oxidant.

The resulting ESR spectrum of the isolated radical shows two main overlapped lines (Fig. S14, ESI $\dagger$ ). The two lines are due to the hyperfine coupling of the unpaired spin of the PTM$^{\bullet}$ moiety with one proton of the vinylene bridge. The isotropic coupling constant $\left(a\left({ }^{1} \mathrm{H}_{\mathrm{a}}\right)=1.9 \mathrm{G}\right)$ was in good agreement with those described for different $(E)$-stilbenoid-based $\mathrm{PTM}^{\bullet}$ compounds coming from their corresponding (E)- $\alpha \mathrm{H}-\mathrm{PTM}$ derivatives. ${ }^{29,30}$ On the other hand, the reddish compound presented the characteristic electronic absorption of conjugated $\mathrm{PTM}^{\bullet}$ radicals. ${ }^{31}$ In particular, the features appearing at 392, 495 and $556 \mathrm{~nm}$ (Table S1, ESI $\dagger$ ) were attributed to the electronic transitions involving the radical frontier orbitals. ${ }^{31}$ In addition, a low-energy broad band was also detected $\left(\lambda_{\max }=811 \mathrm{~nm}, \varepsilon \approx 2875 \mathrm{M}^{-1} \mathrm{~cm}^{-1}\right.$ ) and assigned to an optically induced electron transfer (ET) from the DMA to PTM ${ }^{\bullet}$ unit. TD-DFT calculations (see ESI, $\dagger$ Section S5) supported the assignment. Moreover, previous studies described similar $\lambda_{\max }$ and $\varepsilon$ values for ET bands in analogous $(E)$-isomers of vinylene-bridged PTM-donor dyads ${ }^{27,28,32}$ generated from their corresponding $(E)-\alpha \mathrm{H}-\mathrm{PTM}$ precursors. All at once, both the ESR and NIR data suggested the formation of the $\boldsymbol{E}$ isomer of the PTM ${ }^{\bullet}$-DMA instead of the $Z$ one. At that point, a different synthetic pathway was carried out for obtaining the [(E)-PTM-DMA $]^{\circ}$ isomer. (E)- $\alpha \mathbf{H}$-PTM-DMA, the $(E)$-isomer of the precursor, 
and the intermediate anion $[(\boldsymbol{E}) \text {-PTM-DMA }]^{-}$were considered as starting compounds for the given purpose (see ESI, $\dagger$ Section S2). The resulting radical has identical spectroscopic characteristics than the previous one (Fig. S13, S14 and Table S1, ESI $\dagger$ ). Thus, obtaining the thermodynamically more stable [(E)-PTM-DMA $]^{\bullet}$ isomer irrespective of the $(E / Z)$ configuration of its given precursor was proved.

Redox properties of [(E)-PTM-DMA $]^{\bullet}$ were also studied and compared to the ones described for the [(Z)-PTM-DMA $]^{-}$anion. As shown in Fig. 1C, the two voltammograms are almost identical, which points to a very efficient $(Z) \rightarrow(E)$ isomerization upon oxidation of $[(Z) \text {-PTM-DMA }]^{-}$. This observation prompted us to study the anion-to-radical oxidation process in depth. Two different stages could be distinguished from the monitorization, via UV-Vis electronic absorption spectroscopy, of the stepwise oxidation of [(Z)-PTM-DMA $]^{-}$(Fig. 2A). Up to 1.04 eq. of $\mathrm{Fe}\left(\mathrm{ClO}_{4}\right)_{3}$, a color change from violet to pale orange was observed. Accordingly, once the characteristic UV-Vis band of [(Z)-PTM-DMA $]^{-33}$ vanished, new UV-Vis features at 387, 489, 556 and $780 \mathrm{~nm}$ (Table S1, ESI $\dagger$ ) increased through isosbestic points, indicating the generation of an intermediate PTM $^{\bullet}$ based species. Then, after the addition of a small excess of oxidizing agent (1.25 eq.), an intensification of the color solution took place, turning from pale orange to orange/reddish. At the same time, the UV-Vis electronic absorbance spectra evolved towards the previously described for [(E)-PTMDMA $]^{\bullet}$. In particular, a remarkable red-shift of the bands and an increase in their related absorbance occurred. Identical results were obtained when using $\mathrm{AgNO}_{3}$ as oxidant or via spectroelectrochemistry (Fig. S16, ESI $\dagger$ ). It is known that electronic absorption spectra of stilbenes are generally sensitive to configurational effects. In this line, a red shift in their related UV-Vis features can be seen as long as the extension of $\pi$-conjugation within the stilbene chromophore itself and between the stilbene core and unsaturated auxochromic groups increases. $^{20}$ Thus, this intermediate species was necessarily associated with a less $\pi$-conjugated PTM radical-based species than [(E)-PTM-DMA $]^{\bullet}$.

In line with UV-Vis results, the two stages of the stepwise chemical oxidation of $[(Z) \text {-PTM-DMA }]^{-}$were also differentiated by in situ ESR. As shown in Fig. 2B, the silent response from the anionic species was firstly transformed into a two-line ESR spectrum when 1.04 eq. of oxidant was added. Interestingly, the obtained $a\left({ }^{1} \mathrm{H}_{\mathrm{a}}\right)$ was $2.6 \mathrm{G}$, exceeding in $0.7 \mathrm{G}$ the one observed in the ESR spectrum of [(E)-PTM-DMA $]^{\bullet}$ (Table S1, ESI $\dagger$ ). Thus, a higher amount of spin density in the olefinic hydrogen nucleus is counted on the intermediate radical species. As expected, further oxidation (up to 1.25 eq.) resulted in the evolution of the ESR signal towards the one associated with [(E)-PTM-DMA] (Fig. 2C). Bearing all these findings in mind, the generation of the $[(\boldsymbol{Z}) \text {-PTM-DMA }]^{\bullet}$ isomer radical upon oxidation of [(Z)-PTM-DMA $]^{-}$anion was concluded. According to Scheme 2, a fast one way $Z \rightarrow E$ isomerization reaction mediated by cationic species would occur yielding [(E)-PTMDMA $^{\bullet}$, in good agreement with previous reports in stilbene derivatives. ${ }^{34,35}$ Moreover, taking into account that only a small excess of oxidant was needed (i.e., 0.25 eq.), an electrocatalytic nature of the oxidative isomerization was considered, as equally described for stilbenes ${ }^{20}$ or azobenzenes. ${ }^{18,19}$

Finally, a high excess of oxidant ( $>2$ eq.) provoked a second color evolution when the orange/reddish solution of [(E)-PTMDMA $]^{\bullet}$ turned into dark blue. Analogously, a new main UV-Vis feature was observed at $600 \mathrm{~nm}$ with no hints of ET band (Fig. S18, ESI $\dagger$ ). Hence, the generation of the above mentioned closed-shell cationic species, [(E)-PTM-DMA $]^{+}$, was assumed. The total disappearance of the ESR signal and TD-DFT calculations at a B3LYP/6-31G(d,p) level of theory (Fig. S25 and S26, ESI $\dagger$ ) supported the assignment but, unfortunately, this new species was not stable enough to be isolated.

On the contrary, a totally different behavior was found in the case of ( $\boldsymbol{Z}$ )- $\boldsymbol{\alpha H}$ H-PTM-DMA. The non-radical derivative was subjected to the same chemical oxidation protocol after certifying that the used oxidizing agents have the appropriate redox potentials to form the cation-radical of the amine (Fig. S7, ESI $\dagger$ ). ${ }^{36,37}$ No changes were observed after monitoring by UV-Vis electronic absorption spectroscopy and NMR, demonstrating that the $Z \rightarrow E$ isomerization does not occur. This result brought to light the need of an open-shell (radical) substituent in the stilbene derivative for the $Z \rightarrow E$ isomerization process to happen. DFT calculations at the $(\mathrm{U}) \mathrm{B} 3 \mathrm{LYP} / 6-31 \mathrm{G}(\mathrm{d}, \mathrm{p})$ level of theory were run for the transient cationic species of the radical and non-radical derivatives (see ESI, $\uparrow$ Section S5). As mentioned, it is known that $\mathrm{PTM}^{\bullet}$ may contribute to the stabilization of vicinal charge defects generated upon oxidation, by means of a rapid evolution of the
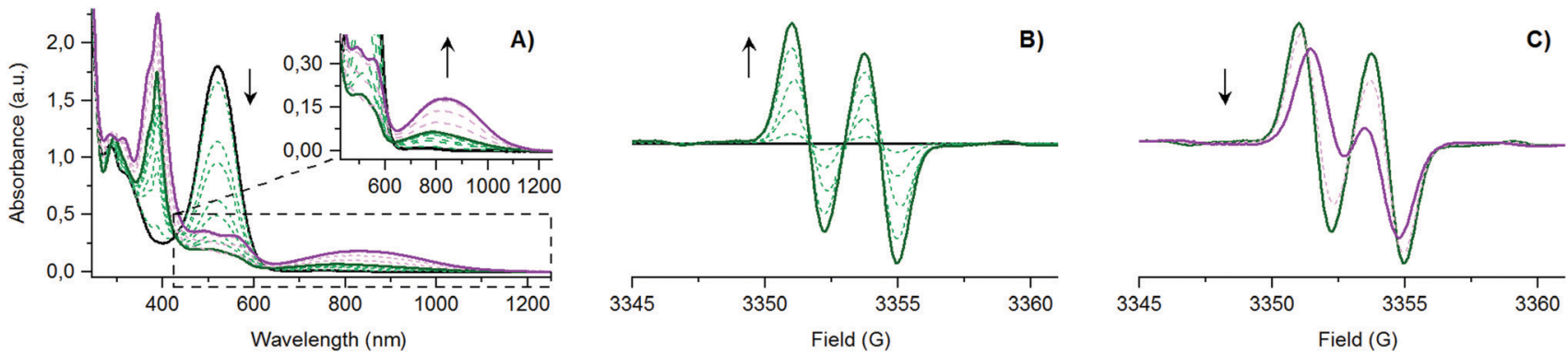

C)

Fig. 2 In situ monitorization via: (A) UV-Vis electronic absorption spectroscopy and (B/C) ESR, of the stepwise chemical oxidation of [(Z)-PTM-DMA] $\left(5 \times 10^{-5} \mathrm{M}\right.$ in THF with $\mathrm{Fe}\left(\mathrm{ClO}_{4}\right)_{3}$ as oxizing agent (ox.), at r.t., according to Scheme 1, reaction $\mathrm{C}$. Same results were obtained with ox $=$ AgNO 3 . $\left[(Z)-\text { PTM-DMA }^{-} \text {: solid black line, [(Z)-PTM-DMA }\right]^{\bullet}$ : solid green line, and [(E)-PTM-DMA $]^{\bullet}$ : solid purple line. 


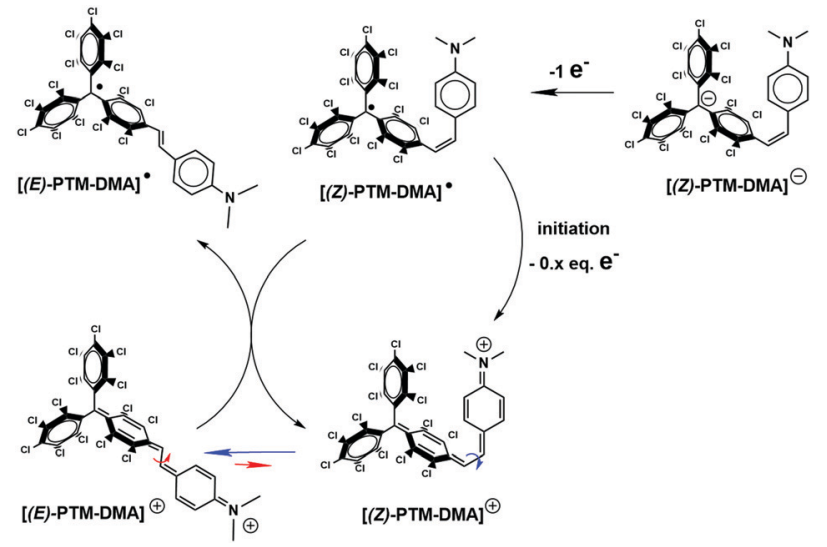

Scheme 2 Proposed mechanism for the oxidation process of [(Z)-PTMDMA $]^{-}$up to $[(E)-P T M-D M A]^{\bullet}$, including the electrocatalytic (i.e., $0 . x$ eq. $\mathrm{e}^{-}$) oxidative $(Z) \rightarrow(E)$ isomerization occurred through the cationic species $[(Z / E)-P T M-D M A]^{+}$.

structure into a closed-shell quinoidal configuration (Fig. S17, ESI $\dagger) .{ }^{26}$ Accordingly, a lower $\pi$ bond order at the central olefinic molecular fragment was found for the cation coming from the open-shell dyad (Table S2, ESI $\dagger$ ) favouring the isomerization. Similar justification was given to explain the $Z / E$ isomerizations by one-electron oxidation of a few non-radical push-pullsubstituted stilbenes. ${ }^{38}$

In summary, further insights into the redox-induced geometric isomerization phenomenon have been gained from the $\pi$-conjugation of an electroactive persistent perchlorotriphenylmethyl $\left(\mathrm{PTM}^{\circ}\right)$ radical moiety to an $E / Z$ switchable stilbene derivative. An electrocatalytic isomerization has been demonstrated to be undoubtedly triggered by the open-shell nature of $\mathrm{PTM}^{\bullet}$ unit. We envisage that the findings here reported, in combination with the already described properties (i.e., magnetic, optical or chiral among others) will enhance the prospects of using the $\mathrm{PTM}^{\bullet}$ unit in smart materials.

This work was supported by the MICIU of Spain (CTQ201680030-R and PID2019-111682RB-I00), the Generalitat de Catalunya (2017-SGR-918) and the MINECO (SEV-2015-0496). J. A. de S. is enrolled in the Materials Science PhD program of UAB. J. A. de S. thanks the Spanish Ministry for the FPI fellowship. The authors acknowledge Dr J. Vidal-Galcedo and Dr Vega Lloveras for the ESR measurements.

\section{Conflicts of interest}

There are no conflicts to declare.

\section{Notes and references}

1 D. Dattler, G. Fuks, J. Heiser, E. Moulin, A. Perrot, X. Yao and N. Giuseppone, Chem. Rev., 2020, 120, 310-433.

2 M.-M. Russew and S. Hecht, Adv. Mater., 2010, 22, 3348-3360.

3 J. Zhang, J. Wang and H. Tian, Mater. Horiz., 2014, 1, 169-184.
4 J. Zhang, Q. Zou and H. Tian, Adv. Mater., 2013, 25, 378-399.

5 D. H. Waldeck, Chem. Rev., 1991, 91, 415-436.

6 A. A. Beharry and G. A. Woolley, Chem. Soc. Rev., 2011, 40, 4422-4437.

7 H. M. D. Bandara and S. C. Burdette, Chem. Soc. Rev., 2012, 41, 1809-1825.

8 I. Aprahamian, Chem. Commun., 2017, 53, 6674-6684.

9 J. B. Birks, Chem. Phys. Lett., 1976, 38, 437-440.

10 G. Orlandi and W. Siebrand, Chem. Phys. Lett., 1975, 30, 352-354.

11 I. Cvrtila, H. Fanlo-Virgós, G. Schaeffer, G. Monreal Santiago and S. Otto, J. Am. Chem. Soc., 2017, 139, 12459-12465.

12 M. A. Gordillo, M. Soto-Monsalve, C. C. Carmona-Vargas, G. Gutiérrez, R. F. D'vries, J.-M. Lehn and M. N. Chaur, Chem. - Eur. J., 2017, 23, 14872-14882.

13 T. Majima, S. Tojo, A. Ishida and S. Takamuku, J. Org. Chem., 1996, 61, 7793-7800.

14 T. Majima, S. Tojo, A. Ishida and S. Takamuku, J. Phys. Chem., 1996, 100, 13615-13623.

15 I. R. Lee, L. Bañares and A. H. Zewail, J. Am. Chem. Soc., 2008, 130, 6708-6709.

16 G. J. Hoijtink and P. H. van der Meij, Zeitschrift für Phys. Chem., 1959, 20, 1-14.

17 M. A. Doran and R. Waack, J. Organomet. Chem., 1965, 3, 94-96.

18 A. Goulet-Hanssens, M. Utecht, D. Mutruc, E. Titov, J. Schwarz, L. Grubert, D. Bléger, P. Saalfrank and S. Hecht, J. Am. Chem. Soc., 2017, 139, 335-341.

19 A. Goulet-Hanssens, C. Rietze, E. Titov, L. Abdullahu, L. Grubert, P. Saalfrank and S. Hecht, Chem, 2018, 4, 1740-1755.

20 M. Linseis, S. Záliš, M. Zabel and R. F. Winter, J. Am. Chem. Soc., 2012, 134, 16671-16692.

21 M. Baroncini, S. Silvi and A. Credi, Chem. Rev., 2020, 120, 200-268.

22 C. Sporer, I. Ratera, D. Ruiz-Molina, J. Vidal Gancedo, K. Wurst, P. Jaitner, C. Rovira and J. Veciana, J. Phys. Chem. Solids, 2004, 65, 753-758.

23 C. Sporer, I. Ratera, D. Ruiz-Molina, Y. Zhao, J. Vidal-Gancedo, K. Wurst, P. Jaitner, K. Clays, A. Persoons, C. Rovira and J. Veciana, Angew. Chem., Int. Ed., 2004, 43, 5266-5268.

24 I. Ratera, S. Marcen, S. Montant, D. Ruiz Molina, C. Rovira, J. Veciana, J. F. Létard and E. Freysz, Chem. Phys. Lett., 2002, 363, 245-251.

25 F. Bejarano, I. Alcon, N. Crivillers, M. Mas-Torrent, S. T. Bromley, J. Veciana and C. Rovira, RSC Adv., 2017, 7, 15278-15283.

26 P. Mayorga Burrezo, C. Franco, R. Caballero, M. Mas-Torrent, F. Langa, J. T. López Navarrete, C. Rovira, J. Veciana and J. Casado, Chem. - Eur. J., 2018, 24, 3776-3783.

27 A. Heckmann and C. Lambert, J. Am. Chem. Soc., 2007, 129, $5515-5527$.

28 A. Heckmann, S. Dümmler, J. Pauli, M. Margraf, J. Köhler, D. Stich, C. Lambert, I. Fischer and U. Resch-Genger, J. Phys. Chem. C, 2009, 113, 20958-20966.

29 C. Rovira, D. Ruiz-Molina, O. Elsner, J. Vidal-Gancedo, J. Bonvoisin, J.-P. Launay and J. Veciana, Chem. - Eur. J., 2001, 7, 240-250.

30 V. Lloveras, J. Vidal-Gancedo, T. M. Figueira-Duarte, J.-F. Nierengarten, J. J. Novoa, F. Mota, N. Ventosa, C. Rovira and J. Veciana, J. Am. Chem. Soc., 2011, 133, 5818-5833.

31 V. Diez-Cabanes, G. Seber, C. Franco, F. Bejarano, N. Crivillers, M. Mas-Torrent, J. Veciana, C. Rovira and J. Cornil, ChemPhysChem, 2018, 19, 2572-2578.

32 I. Ratera, C. Sporer, D. Ruiz-Molina, N. Ventosa, J. Baggerman, A. M. Brouwer, C. Rovira and J. Veciana, J. Am. Chem. Soc., 2007, 129, 6117-6129.

33 J. Veciana, J. Riera, J. Castañer and N. Ferrer, J. Organomet. Chem., 1985, 297, 131-141.

34 Y. Kuriyama, T. Arai, H. Sakuragi and K. Tokumaru, Chem. Phys. Lett., 1990, 173, 253-256.

35 F. D. Lewis, A. M. Bedell, R. E. Dykstra, J. E. Elbert, I. R. Gould and S. Farid, J. Am. Chem. Soc., 1990, 112, 8055-8064.

36 N. G. Connelly and W. E. Geiger, Chem. Rev., 1996, 96, 877-910.

37 B. Kratochvil and R. Long, Anal. Chem., 1970, 42, 43-46.

38 H. Spreitzer, M. Scholz, G. Gescheidt and J. Daub, Liebigs Ann., 1996, 1996, 2069-2077. 